\title{
DESENVOLVIMENTO INICIAL DO CAFÉ CONILLON (COFFEA CANEPHORA PIERRE) EM SOLOS DE DIFERENTES TEXTURAS COM MUDAS PRODUZIDAS EN DIFERENTES SUBSTRATOS
}

\author{
INITIAL DEVELOPMENT OF CONILLON COFFEE (COFFEA \\ CANEPHORA PIERRE) IN SOILS WITH DIFFERENT TEXTURES \\ USING SEEDLINGS PRODUCED IN DIFFERENT SUBSTRATES \\ Heder Braun ${ }^{1}$; João Henrique Zonta ${ }^{2}$; Julião Soares de Souza Lima ${ }^{3}$; \\ Edvaldo Fialho dos Reis ${ }^{4}$; Danilo Paulucio da Silva ${ }^{5}$
}

\section{RESUMO}

Objetivou-se avaliar o desenvolvimento inicial do café conillon (Coffea canephora Pierre) em solos de diferentes texturas com mudas produzidas em diferentes substratos. O experimento foi realizado em casa de vegetação, localizada em Alegre-ES, utilizando mudas de café conillon (Coffea canephora Pierre). As mudas foram produzidas em tubetes contendo os seguintes substratos: Plantmax ${ }^{\circledR}$ + terra (proporção 1:1 v/v); substrato caseiro (terra misturada com esterco bovino e areia na proporção de 1:1:1 v/v/v); Plantmax ${ }^{\circledR}$ e terra + palha de café (proporção 1:1 v/v). Após 140 dias, as mudas foram transplantadas para baldes de $10 \mathrm{~L}$ contendo dois tipos de solo: solo de testura argilo-arenosa e argilosa, constituindo um esquema fatorial 4x2, com substratos em 4 níveis e solo em 2 níveis, num delineamento inteiramente casualizado, com três repetições. Aos 150 dias pós-plantio, foram avaliados os seguintes parâmetros agronômicos: altura das mudas, diâmetro do caule, diâmetro da copa, área foliar, massa fresca e seca da parte aérea e massa fresca e seca do sistema radicular. A interação que promoveu o melhor desenvolvimento inicial da cultura do café conillon se constitui em mudas produzidas em substrato comercial + terra, transplantas para solo de textura argilo-arenosa.

Palavras-chave: Coffea canephora Pierre, solo, substrato.

\begin{abstract}
The objective of this work was to evaluate the initial development of conillon coffee (Coffea canephora Pierre) in soils with different textures using seedlings produced in different substrates. The experiment was conducted in greenhouse, in the Municipal District of Alegre-Es, using seedlings of conillon coffee (Coffea canephora Pierre). The seedlings were produced in plastic tubes containing the following substrates: Plantmax ${ }^{\circledR}+$ soil $(1: 1 \mathrm{v} / \mathrm{v})$; homemade substrate (soil + bovine manure + sand 1:1:1 v/v/v); and Plantmax ${ }^{\circledR}($ soil + coffee husk 1:1 v/v). After 140 days, the seedlings were transplanted to 10-L containers with two types of soil: sandy-clay and clay textures, in a $4 X 2$ fatorial arrangement (4 levels of substrate and 2 levels of soil), in a complete randomized design, with three repetitions. At 150 days post-planting, the following agronomic parameters were evaluated: seedling height, stem diameter, crown diameter, leaf area, fresh and dry mass of aerial part and fresh and dry mass of root system. The treatment comprising seedlings produced in commercial substrate + soil followed by transplanting to soil with sandy-clay texture provided the best initial development of conillon coffee.
\end{abstract}

Key words: Coffea canephora Pierre, soil, substrate.

1 Universidade Federal de Viçosa, UFV, Viçosa - MG, Cep: 36570-000, e-mail: hederbraun@ hotmail.com

2 Departamento de Engenharia Agrícola, Universidade Federal de Viçosa, UFV, Viçosa - MG, Cep: 36570-000, e-mail: joaozonta@hotmail.com

3 Departamento de Engenharia Rural, Centro de Ciências Agrárias da Universidade Federal do Espírito Santo, Alegre - ES, Cep 29500-000, e-mail: limajss@yahoo.com.br

4 Departamento de Engenharia Rural, Centro de Ciências Agrárias da Universidade Federal do Espírito Santo, Alegre - ES, Cep 29500-000, e-mail: edereis@cca.ufes.br

5 Departamento de Engenharia Agrícola, Universidade Federal de Viçosa, UFV, Viçosa - MG, Cep: 36570-000, e-mail: daniloagronomia@yahoo.com.b

Fecha de Recepción: 12 Septiembre 2007

Fecha de Aceptación: 07 Enero 2008 


\section{INTRODUÇÃO}

A produção de mudas de alta qualidade genética e fitossanitária constitui-se um requisito indispensável para alcançar elevadas produtividades na agricultura. Apesar de ser um entre vários fatores envolvidos na produção, as mudas devem ser produzidas dentro de padrões mínimos de qualidade para se obter sucesso no empreendimento.

Para a produção de mudas de cafeeiro, os sacos plásticos têm sido recomendados e são os recipientes mais utilizados atualmente. Esses recipientes comportam um volume de substrato que permite a obtenção de mudas vigorosas e de qualidade adequada para o plantio. Por outro lado, contribuem para o aumento da área requerida para o viveiro e a elevação do custo de produção, de transporte e plantio da muda. Aliada a estes aspectos, há também a possibilidade de contaminação das mudas por nematóides em decorrência do substrato que é normalmente utilizado para o seu enchimento (Melo, 1999).

A produção de mudas de cafeeiro em tubetes, facilita sobremaneira o isolamento de viveiro, a proteção contra nematóides e outras doenças do solo, apresenta maior facilidade no controle de pragas e doenças da parte aérea e preserva a integridade do sistema radicular durante a fase inicial da produção da muda (Lima, 1986).

O sistema de produção de mudas em tubetes apresenta vantagens em relação ao sistema convencional, tais como: formação de sistema radicular sem enovelamento, crescimento inicial das mudas após o plantio mais rápido e facilidades operacionais a quantidade de mudas transportadas por caminhão é cinco a seis vezes maior, o peso é duas a duas vezes e meia menor e rendimento de plantio, até três vezes maior, quando comparado com o sistema convencional (Simões, 1987). Uma outra vantagem é a maior facilidade para o manejo das mudas no viveiro, incluindo adubações, pulverizações contra pragas e doenças e irrigações, uma vez que os tubetes ficam suspensos a certa altura do solo.

Substrato é a mistura de materiais usada no desenvolvimento de mudas, sustentando e fornecendo nutrientes à planta. Pode ser de origem vegetal, animal ou mineral, sendo constituído por uma parte sólida (partículas minerais e orgânicas) e pelo espaço poroso, que é ocupado por água ou ar. O desenvolvimento do sistema radicular é influenciado pela aeração do substrato, que depende da composição de suas partículas. O substrato exerce influência significativa sobre a arquitetura do sistema radicular e o estado nutricional das plantas (Spurr \& Barnes, 1973, citados por Guimarães et al., 1998). Campinhos Júnior \& Ikemori (1983), Consideram inadequado o uso de materiais de origem mineral (argila e areia) para a produção de mudas em tubetes, em razão do peso e desagregação do substrato, e por não serem estéreis.

Após o transplantio das mudas para o campo, um dos fatores de maior influência é o tipo de solo da área. Segundo Lynch (1995), a textura e estrutura de solo afetam o sistema radicular das plantas, que apresenta características diferenciadas de acordo com as características do solo.

Objetivou-se avaliar o desenvolvimento inicial do café conillon (Coffea canephora Pierre) em solos de diferentes texturas com mudas produzidas em diferentes substratos.

\section{MATERIAIS E MÉTODOS}

O experimento foi realizado em casa de vegetação, localizada no Centro de Ciências Agrárias da Universidade Federal do Espírito Santo, em Alegre - ES, latitude de $20^{\circ} 45^{\prime} 40,42^{\prime \prime} \mathrm{S}$ e longitude $41^{\circ}$ 32' 06,73" W e altitude de 247 metros.

Para a realização do experimento, foram utilizadas mudas de café conillon (Coffea canephora Pierre), produzidas a partir de estacas obtidas do tecido adulto de ramos ortotrópicos, sendo estas retiradas de lavouras com bom aspecto fitossanitário e nutricional. Após a retirada dos ramos das plantas mãe, estes foram encaminhados para a casa de vegetação, local onde foram eliminados $30 \mathrm{~cm}$ das extremidades dos ramos ortotrópicos. Em seguida foi realizado a padronização das estacas, com 6 a $8 \mathrm{~cm}$ de altura, folhas com $1 / 3$ do limbo foliar, ramos plagiotrópicos e acima da inserção do par de folha com $1 \mathrm{~cm}$.

Após a obtenção das estacas, estas foram previamente enraizadas em caixas de areia e, transplantadas para tubetes de $14 \mathrm{~cm}$ de altura, $3,5 \mathrm{~cm}$ de diâmetro interno na abertura superior e $1,5 \mathrm{~cm}$ de diâmetro na abertura inferior da extremidade afunilada e possuem um volume aproximado de $120 \mathrm{~mL}$ (Melo, 1999), contendo os seguintes substratos: Plantmax ${ }^{\circledR}$ + terra (proporção 1:1 v/v); substrato caseiro (terra misturada com esterco bovino e areia na proporção de 1:1:1 v/v/v); Plantmax ${ }^{\circledR}$ (mistura de matéria or- 
gânica de origem vegetal e vermiculita expandida); terra + palha de café (proporção 1:1 v/v). As mudas permaneceram por 140 dias nos tubetes, sendo então transplantadas para baldes de 10 litros, contendo solo de textura argilo-arenosa e argilosa, retirados de um barranco. Assim, o experimento foi montado em um esquema fatorial 4 × 2 , sendo 4 níveis de substrato e 2 níveis de solo, com 3 repetições, em delineamento inteiramente casualizado.

Previamente ao enchimento dos baldes, os solos foram destorroados e passados em peneira de $4 \mathrm{~mm}$ e homogeneizados. Foi realizada correção do solo e adubação de plantio, segundo recomendações técnicas para a cultura do cafeeiro no Espírito Santo (Dadalto, 2001). Durante a condução do experimento, foram realizados irrigações, manejo de pragas e doenças e controle de plantas daninhas de acordo com a necessidade da cultura.
Aos 150 dias pós-plantio, foram avaliados os seguintes parâmetros agronômicos: altura das mudas $(\mathrm{cm})$ : determinada com auxilio de régua graduada; diâmetro do caule $(\mathrm{cm})$ : determinado através de paquímetro; diâmetro da copa $(\mathrm{cm})$ : determinado com auxilio de régua graduada; área foliar $\left(\mathrm{cm}^{2}\right)$ : determinada com medidor LI-COR 3100; massa fresca da parte aérea e do sistema radicular $(\mathrm{g})$ : determinada através de pesagem individual de cada planta, com uso de balança analítica com precisão de 0,01g; massa seca da parte aérea e do sistema radicular (g): efetuando-se a secagem em estufa a $70^{\circ} \mathrm{C}$ e pesando-se em balança analítica até atingirem peso constante (AOAC, 1984);

Os dados obtidos foram submetidos à análise de variância, e os fatores significativos analisados pelo teste de Tukey a nível de significância de 5\% de probabilidade.

Tabela 1

Características químicas do solo de textura argilosa utilizado na condução do experimento

\begin{tabular}{|c|c|c|c|c|c|c|c|c|c|c|c|}
\hline pH & $\mathbf{P}$ & $\mathbf{K}$ & $\mathbf{C a}$ & Mg & $\mathbf{N a}$ & Al & $\mathbf{H}+\mathbf{A l}$ & S.B. & CTC & $\mathbf{t}$ & $\mathbf{V}$ \\
\hline Acidez & Fósforo & Potássio & Cálcio & Magnésio & Sódio & Alumínio & $\begin{array}{c}\text { Ac. } \\
\text { Potencial }\end{array}$ & $\begin{array}{l}\text { Soma } \\
\text { Bases }\end{array}$ & $\begin{array}{c}\text { Cap. Troca } \\
\text { Cat. }\end{array}$ & $\begin{array}{c}\text { CTC } \\
\text { efetiva }\end{array}$ & $\begin{array}{l}\text { Sat. } \\
\text { Bases }\end{array}$ \\
\hline & $\mathrm{mg} / \mathrm{dm}^{3}$ & $\mathrm{mg} / \mathrm{dm}^{3}$ & $\mathrm{cmol}^{\mathrm{c}} \mathrm{dm}^{3}$ & $\mathrm{cmol}_{\mathrm{c}} \mathrm{dm}^{3}$ & $\mathrm{mg} / \mathrm{dm}^{3}$ & $\mathrm{cmol}_{\mathrm{c}} \mathrm{dm}^{3}$ & $\mathrm{cmol}_{\mathrm{c}} \mathrm{dm}^{3}$ & $\mathrm{cmol} / \mathrm{cdm}^{3}$ & $\mathrm{cmol} / \mathrm{cdm}^{3}$ & $\mathrm{cmol} / \mathrm{cm}^{3}$ & $\%$ \\
\hline 6.2 & 12.0 & 74.0 & 1.8 & 0.7 & 3.0 & 0.0 & 1.5 & 2.7 & 4.2 & 2.7 & 64.3 \\
\hline
\end{tabular}

Tabela 2

Características químicas do solo de textura argilosa utilizado na condução do experimento

\begin{tabular}{|c|c|c|c|c|c|c|c|c|c|c|c|}
\hline $\mathbf{p H}$ & $\mathbf{P}$ & $\mathbf{K}$ & $\mathbf{C a}$ & $\mathbf{M g}$ & $\mathbf{N a}$ & $\mathbf{A l}$ & $\mathbf{H}+\mathbf{A l}$ & S.B. & CTC & t & V \\
\hline Acidez & Fósforo & Potássio & Cálcio & Magnésio & Sódio & Alumínio & $\begin{array}{c}\text { Ac. } \\
\text { Potencial }\end{array}$ & $\begin{array}{c}\text { Soma } \\
\text { Bases }\end{array}$ & $\begin{array}{c}\text { Cap. Troca } \\
\text { Cat. }\end{array}$ & $\begin{array}{c}\text { CTC } \\
\text { efetiva }\end{array}$ & $\begin{array}{c}\text { Sat. } \\
\text { Bases }\end{array}$ \\
\hline & $\mathrm{mg} / \mathrm{dm}^{3}$ & $\mathrm{mg} / \mathrm{dm}^{3}$ & $\mathrm{cmol} / \mathrm{cm}^{3}$ & $\mathrm{cmol} / \mathrm{dm}^{3}$ & $\mathrm{mg} / \mathrm{dm}^{3}$ & $\mathrm{cmol}_{\mathrm{c}} \mathrm{dm}^{3}$ & $\mathrm{cmol} / \mathrm{cm}^{3}$ & $\mathrm{cmol} / \mathrm{cm}^{3}$ & $\mathrm{cmol}_{\mathrm{c}} \mathrm{dm}^{3}$ & $\mathrm{cmol}_{\mathrm{c}} \mathrm{dm}^{3}$ & $\%$ \\
\hline 6.1 & 7.0 & 111.0 & 0.9 & 0.7 & 4.0 & 0.0 & 1.2 & 1.9 & 3.1 & 1.9 & 61.3 \\
\hline
\end{tabular}

Tabela 3

Análise granulométrica dos solos utilizados na condução do experimento

\begin{tabular}{|c|c|c|c|}
\hline Textura & Areia (g/kg) & Argila (g/kg) & Silte (g/kg) \\
\hline Argilosa & 400 & 530 & 70 \\
\hline Argilo-arenosa & 651 & 310 & 39 \\
\hline
\end{tabular}




\section{RESULTADOS E DISCUSSÃO}

Os valores de altura e diâmetro do caule das plantas de café conillon, com mudas produzidas em diferentes substratos e transplantadas em diferentes tipos de solo são apresentados na Tabela 4.

As características altura e diâmetro do caule das plantas foram afetados pelo tipo de substrato, tipo de solo e pela interação entre esses fatores (Tabela 4). O substrato comercial + terra proporcionou maior desenvolvimento das plantas em altura no solo de textura argilo-arenosa, mas não diferindo estatisticamente do substrato caseiro. Cunha et al. (2002), citam que o melhor substrato a ser usado para produção de mudas de café em tubetes é o comercial, seguido do substrato alternativo composto a partir de esterco bovino. No solo de textura argilosa o substrato contendo palha de café + terra foi o que proporcionou maior desenvolvimento para essa característica. Da mesma forma ocorreu para o diâmetro do caule das plantas que, tanto no solo de textura argilo-arenosa e argilosa, os substratos caseiro e palha de café + terra não apresentaram diferenças significativas entre si.

Os valores de diâmetro da copa e área foliar das plantas de café conillon, com mudas produzidas em diferentes substratos e transplantadas em diferentes tipos de solo são apresentados na Tabela 5 .

Com relação ao diâmetro da copa, houve diferença estatística dos substratos dentro do solo de textura argilo-arenosa, sendo o melhores resultados obtidos com as mudas produzidas em comercial + terra e caseiro (Tabela 5). Dentro do solo argiloso não houve diferença estatística entre os substratos. Podemos observar que as duas texturas de solo, associadas aos substratos, apresentaram diferença estatística apenas para o substrato palha de café + terra.

Para área foliar, houve diferença estatística dos substratos dentro das duas texturas de solo, sendo o substrato comercial + terra e o caseiro os

Tabela 4

Valores médios para altura das plantas $(\mathrm{cm})$ e diâmetro do caule das mudas, em função dos substratos e duas textura de solo

\begin{tabular}{|c|c|c|c|c|}
\hline \multirow{2}{*}{ Substrato } & \multicolumn{2}{|c|}{ Altura das plantas (cm) } & \multicolumn{2}{|c|}{ Diâmetro do caule (cm) } \\
\hline & Argilo-arenosa & Argilosa & Argilo-arenosa & Argilosa \\
\hline Plantmax $^{\circledR}+$ terra & $24,3 \mathrm{aA}$ & $15,16 \mathrm{bAB}$ & $0,39 \mathrm{aA}$ & $0,27 \mathrm{bBC}$ \\
\hline Caseiro & $21,93 \mathrm{aA}$ & $15,56 \mathrm{bAB}$ & $0,35 \mathrm{aAB}$ & $0,36 \mathrm{aA}$ \\
\hline Palha café + terra & $13,16 \mathrm{bB}$ & $17,83 \mathrm{aA}$ & $0,24 \mathrm{bC}$ & $0,33 \mathrm{aAB}$ \\
\hline Plantmax ${ }^{\circledR}$ & $16,16 \mathrm{aB}$ & $11,60 \mathrm{bB}$ & $0,29 \mathrm{aBC}$ & $0,26 \mathrm{aC}$ \\
\hline
\end{tabular}

* Médias seguidas pela mesma letra maiúscula na coluna e minúscula na linha não se diferenciam estatisticamente pelo teste de Tukey a $5 \%$ de probabilidade.

Tabela 5

Valores médios para diâmetro da copa $(\mathrm{cm})$ e área foliar $(\mathrm{cm} 2)$ das mudas, em função dos substratos e duas textura de solo

\begin{tabular}{|l|c|c|c|c|}
\hline \multirow{2}{*}{ Substrato } & \multicolumn{2}{|c|}{ Diâmetro da copa (cm) } & \multicolumn{2}{c|}{ Área foliar $\left(\mathbf{c m}^{2}\right)$} \\
\cline { 2 - 5 } & Argilo-arenosa & Argilosa & Argilo-arenosa & Argilosa \\
\hline Plantmax $^{\circledR}+$ terra & $27,13 \mathrm{aA}$ & $25,16 \mathrm{aA}$ & $481,84 \mathrm{aA}$ & $18,29 \mathrm{bAB}$ \\
\hline Caseiro & $26,33 \mathrm{aA}$ & $24,66 \mathrm{aA}$ & $516,61 \mathrm{aA}$ & $252,01 \mathrm{bA}$ \\
\hline Palha café + terra & $20,2 \mathrm{bB}$ & $25,13 \mathrm{aA}$ & $350,11 \mathrm{aB}$ & $69,18 \mathrm{bC}$ \\
\hline Plantmax & & $21,06 \mathrm{aA}$ & $150,22 \mathrm{aC}$ & $\mathrm{aAB}$ \\
\hline
\end{tabular}

* Médias seguidas pela mesma letra maiúscula na coluna e minúscula na linha não se diferenciam estatisticamente pelo teste de Tukey a $5 \%$ de probabilidade. 
que apresentaram os melhores resultados. Andrade Neto (1998), trabalhando com dois tipos de adubação e diferentes fontes de matéria orgânica, constatou que o esterco de curral na proporção de $80 \%$ adubado com o fertilizante de liberação lenta (osmocote) foi o que apresentou os maiores valores para as características altura da planta, área foliar e matérias secas do sistema radicular e parte aérea. Ainda, segundo o mesmo autor, estes substratos promoveram os mesmos resultados que o substrato comercial fertilizado.

Analisando os diferentes substratos, as duas texturas de solo apresentaram diferença entre si, com o solo de textura argilo-arenosa tendo o melhor desempenho (Tabela 5).

Os valores de massa fresca e seca da parte aérea das plantas de café conillon, com mudas produzidas em diferentes substratos e transplantadas em diferentes tipos de solo são apresentados na Tabela 6 .
Houve diferença estatística da massa fresca e seca da parte aérea, quando comparados os substratos ao nível das texturas do solo (Tabela 6). No solo de textura argilo-arenosa, os melhores resultados tanto para massa fresca quanto para massa seca da parte aérea foram obtidos com uso dos substratos comercial + terra e caseiro. No solo de textura argilosa, os melhores resultados tanto para massa fresca quanto para massa seca da parte aérea foram obtidos com uso do substrato palha de café + terra.

Quando comparadas às duas texturas de solo ao nível dos substratos, podemos observar que ocorreu diferença estatística tanto para massa fresca quanto para massa seca da parte aérea (Tabela 6). Para massa fresca da parte aérea, o solo de textura argilo-arenosa obteve resultados superiores para todos os substratos. Para massa seca da parte aérea o solo de textura argilo-arenosa obteve resultados superiores, exceto

Tabela 6

Valores médios para massa fresca e seca da parte aérea (g) das mudas, em função dos substratos e duas textura de solo

\begin{tabular}{|l|c|c|c|c|}
\hline \multirow{2}{*}{ Substrato } & \multicolumn{2}{|c|}{ Massa fresca parte aérea (g) } & \multicolumn{2}{c|}{ Massa seca parte aérea (g) } \\
\cline { 2 - 5 } & Argilo-arenosa & Argilosa & Argilo-arenosa & Argilosa \\
\hline Plantmax $^{\circledR}+$ terra & $17,36 \mathrm{aA}$ & $8,24 \mathrm{bB}$ & $6,92 \mathrm{aA}$ & $3,02 \mathrm{bB}$ \\
\hline Caseiro & $16,71 \mathrm{aA}$ & $6,52 \mathrm{bC}$ & $6,29 \mathrm{aA}$ & $2,62 \mathrm{bB}$ \\
\hline Palha café + terra & $10,71 \mathrm{aB}$ & $9,88 \mathrm{bA}$ & $3,91 \mathrm{bB}$ & $4,65 \mathrm{aA}$ \\
\hline Plantmax $^{\circledR}$ & $5,17 \mathrm{aC}$ & $2,89 \mathrm{bD}$ & $2,33 \mathrm{aB}$ & $1,34 \mathrm{aC}$ \\
\hline
\end{tabular}

* Médias seguidas pela mesma letra maiúscula na coluna e minúscula na linha não se diferenciam estatisticamente pelo teste de Tukey a $5 \%$ de probabilidade.

Tabela 7

Valores médios para massa fresca e seca do sistema radicular (g) das mudas, em função dos substratos e solo

\begin{tabular}{|l|c|c|c|c|}
\hline \multirow{2}{*}{ Substrato } & \multicolumn{2}{|c|}{ Massa fresca do sistema radicular $(\mathbf{g})$} & \multicolumn{2}{c|}{ Massa seca do sistema radicular (g) } \\
\cline { 2 - 5 } & Argilo-arenosa & Argilosa & Argilo-arenosa & Argilosa \\
\hline Plantmax $^{\circledR}+$ terra & $10,96 \mathrm{aA}$ & $5,16 \mathrm{bA}$ & $4,37 \mathrm{aA}$ & $1,45 \mathrm{bAB}$ \\
\hline Caseiro & $9,01 \mathrm{aB}$ & $2,81 \mathrm{bB}$ & $3,16 \mathrm{aA}$ & $1,35 \mathrm{bAB}$ \\
\hline Palha café + terra & $8,05 \mathrm{aB}$ & $5,26 \mathrm{bA}$ & $2,09 \mathrm{aBC}$ & $2,59 \mathrm{aA}$ \\
\hline Plantmax $^{\circledR}$ & $2,61 \mathrm{aC}$ & $1,49 \mathrm{aB}$ & $0,83 \mathrm{aC}$ & $0,40 \mathrm{aB}$ \\
\hline
\end{tabular}

* Médias seguidas pela mesma letra maiúscula na coluna e minúscula na linha não se diferenciam estatisticamente pelo teste de Tukey a $5 \%$ de probabilidade. 
para o substrato palha de café + terra, no qual o solo de textura argilosa mostrou-se superior.

Os valores de massa fresca e seca o sistema radicular das plantas de café conillon, com mudas produzidas em diferentes substratos e transplantadas em diferentes tipos de solo são apresentados na Tabela 6.

Houve diferença estatística da massa fresca e seca do sistema radicular, quando comparados os substratos ao nível da textura do solo e também quando comparadas as duas texturas do solo ao nível dos substratos (Tabela 7). O solo de textura argilo-arenosa apresentou melhor desempenho tanto para massa fresca quanto para massa seca do sistema radicular em todos os tipos de substratos. Este resultado pode ser atribuído a uma possível compactação ocorrida no solo de textura argilosa, proporcionando uma condição inadequada para o desenvolvimento radicular, corroborando com

\section{REFERÊNCIAS}

ANDRADE NETO,A. DE 1998. Avaliação de substratos alternativos e tipos de adubação para a produção de mudas de cafeeiro (Coffea arabica L.) em tubetes. 65 p. Dissertação (Mestrado em Fitotecnia) - Universidade Federal de Lavras, Lavras.

ASSOCIATION OF OFFICIAL AGRICULTURAL CHEMISTS (Washington, DC) 1984. Official methods of analysis. 9. ed. Washington, DC.: AOAC 832 p.

CAMPINHOS JUNIOR, E.; IKEMORI, Y.K. 1983. Introdução de nova técnica na produção de mudas de essências florestais. Silvicultura, São Paulo, v. 8, n. 28, p. 226-228.

CUNHA, R.L.DA; SOUZA, C.A.S.; NETO, A.A.; MELO, B.; CORRÊA, J.F. 2002. Avaliação de substratos e tamanhos de recipientes na formação de mudas de cafeeiros (coffea arabica 1.) em tubetes. Ciência Agrotécnica, Lavras, v. 26, n. 1, p. 7-12.

DADALTO, G.G.; FULLIN, E.A. 2001. Manual de recomendação de calagem e adubação para o Estado do Espírito Santo - $4^{\text {a }}$ aproximação. Vitória, ES: SEEA/INCAPER 266 p. a afirmação de Lynch (1995), na qual o sistema radicular das plantas apresenta características diferenciadas de acordo com textura do solo. Este resultado é de suma importância, pois a quantidade de raízes demonstra a capacidade de absorção de água e de nutrientes pela planta (Guimarães et al., 1996).

O substrato comercial + terra apresentou melhores resultados tanto para massa fresca quanto para massa seca do sistema radicular em ambos os solos.

\section{CONCLUSÃO}

A interação que promoveu o melhor desenvolvimento inicial da cultura do café conillon se constitui em mudas produzidas em substrato comercial + terra, transplantas para solo de textura argilo-arenosa.

GUIMARÃES, C.M.; BRUNINI, O.; STONE, L.F. 1996. Adaptação do feijoeiro (Phaseolus vulgaris L.) à seca. 1. Densidade e eficiência radicular. Pesquisa Agropecuária Brasileira, v. 31, p. 393-399.

GUIMARÃES, P.T.G.; ANDRADE NETO, A.; BELLINI JUNIOR, O.; ADÃO, W.A.; SILVA, E.M. 1998. A produção de mudas de cafeeiros em tubetes. Informe Agropecuário, Belo Horizonte, v. 19, n. 193, p. 98-109.

LIMA, J.E.O. DE. 1986. Novas técnicas de produção de mudas cítricas. Laranja, Cordeirópolis, v.2, n.7, p. 463-468.

LYNCH, L. 1995. Root architecture and plant productivity. Plant Physiology, v. 109, p. 7-13.

MELO, B. DE. 1999. Estudos sobre produção de mudas de cafeeiros (Coffea arabica L.) em tubetes. 119 p. Tese (Doutorado em Fitotecnia) - Universidade Federal de Lavras, Lavras.

SIMÕES, J.W. 1987. Problemática da produção de mudas em essências florestais. Piracicaba: IPEF, 29 p. (EPAGRI. Boletim técnico 73). 